\title{
Continuous synthesis of pyridocarbazoles and initial photophysical and bioprobe characterization $\dagger$
}

\author{
D. Tyler McQuade, ${ }^{\text {*ab }}$ Alexander G. O'Brien, ${ }^{a}$ Markus Dörr, ${ }^{c}$ Rajathees Rajaratnam, ${ }^{c}$ \\ Ursula Eisold, ${ }^{d}$ Bopanna Monnanda, ${ }^{a}$ Tomoya Nobuta, ${ }^{a}$ Hans-Gerd Löhmannsröben, ${ }^{d}$ \\ Eric Meggers ${ }^{c}$ and Peter H. Seeberger ${ }^{\text {ae }}$
}

\begin{abstract}
Pyridocarbazoles when ligated to transition metals yield high affinity kinase inhibitors. While batch photocyclizations enable the synthesis of these heterocycles, the non-oxidative Mallory reaction only provides modest yields and difficult to purify mixtures. We demonstrate here that a flow-based Mallory cyclization provides superior results and enables observation of a clear isobestic point. The flow method allowed us to rapidly synthesize ten pyridocarbazoles and for the first time to document their interesting photophysical attributes. Preliminary characterization reveals that these molecules might be a new class of fluorescent bioprobe.
\end{abstract}

Received 1st July 2013

Accepted 30th July 2013

DOI: $10.1039 / c 3 s c 51846 a$

www.rsc.org/chemicalscience
Recently a family of complexes ${ }^{1}$ exhibiting high affinities and selectivities for individual protein kinases was reported. ${ }^{2}$ These inhibitors are powerful signal transduction probes and may eventually lead to transition metal-based drugs. ${ }^{3}$ The inspiration for the GSK-3 inhibitor (2, one representative of this family of complexes $)^{4}$ was the natural product staurosporine (1) in which the indolocarbazole glycine was mimicked by the novel pyrido[2,3-a]pyrrolo[3,4-c]carbazole-5,7(6H)-dione ligand. A key step in the synthesis of such pyridocarbazole ligands is a $6 \pi$-photoelectrocyclization (eqn (1)).

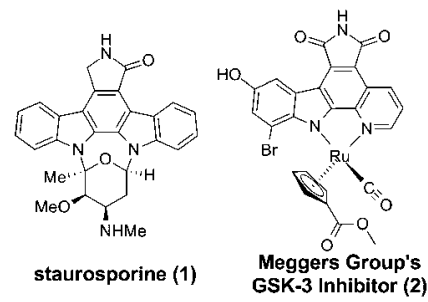

The success of this class of heterocycles in combination with difficulties in scaling up the photochemical cyclization

${ }^{a}$ Department for Biomolecular Systems, Max Planck Institute for Colloids and Interfaces, Am Mühlenberg 1, 14476 Potsdam, Germany. E-mail: tyler.mcquade@ mpikg.mpg.de

${ }^{b}$ Department of Chemistry and Biochemistry, Florida State University, Tallahassee, FL 32306, USA

'Fachbereich Chemie, Philipps-Universität Marburg, Hans-Meerwein-Straße, 35043 Marburg, Germany

${ }^{d}$ Potsdam Institut für Chemie, Karl-Liebknecht-Str. 24-25, Haus 25, 14476 Golm, Germany

${ }^{e}$ Freie Universität Berlin, Arnimallee 22, 14195 Berlin, Germany; Web: http://www. mpikg.mpg.de

$\dagger$ Electronic supplementary information (ESI) available. See DOI: $10.1039 / \mathrm{c} 3 \mathrm{sc} 51846 \mathrm{a}$ prompted us to investigate the potential of using a continuous photocyclization for the production of pyridocarbazoles. Herein, we demonstrate that cleaner, high yield photocyclizations are achieved using flow. In addition, we also learned more about the mechanism of cyclization. Finally, the rapid synthesis enables qualitative comparison of the photophysical properties of 10 pyridocarbazoles and from this collection, we obtained absorption, emission and lifetime data for four of the compounds. We also demonstrated that these species can stain cells and remain fluorescent under physiological conditions.

Photoelectrocyclizations enable conversion of simple starting materials into complex structures. ${ }^{5}$ Low yields and difficult separations, however, make these reactions challenging. ${ }^{6}$ Photocyclizations such as the Mallory reaction often yield products that are also photoactive and long reaction times can lead to byproducts that lower yields and confound purification and scale up. ${ }^{7}$ We and others have recently demonstrated that continuous flow photoreactors offer many advantages including faster reaction times due to higher photon flux, higher throughput and increased yield. ${ }^{8,9}$

The conversion of 3 to 4 (eqn (1)) is predicted to proceed via (1) a radical mechanism at $\lambda<300 \mathrm{~nm}$ (ref 10) or (2) an electrocyclization followed by $\mathrm{HBr}$ elimination at $\lambda>300 \mathrm{~nm} .{ }^{5}$ The best results in batch were observed at $366 \mathrm{~nm}$ excitation and thus we selected this wavelength to begin surveying flow conditions. ${ }^{2}$ We started by measuring the reaction progress as a function of residence time using a flow photoreactor similar to that described by Booker-Millburn et al. ${ }^{11}$ Briefly, a $400 \mathrm{~W}$ medium pressure $\mathrm{Hg}$ lamp nested in a water-cooled glass cylinder was wrapped with $762 \mu \mathrm{m}$ ID FEP tubing to provide an "analytical" reactor $(695 \mu \mathrm{L})$ and a "preparative" reactor $(5 \mathrm{~mL}) .{ }^{12}$ We selected the transformation of 3 to 4 because both 
are soluble in toluene. A solution of $3\left(1 \mathrm{mg} \mathrm{mL} \mathrm{m}^{-1}\right)$ was drawn through the tubular microreactor using a syringe pump at flow rates corresponding to the residence times described in Fig. 1B. Each reaction used $2 \mathrm{mg}$ of material (Fig. 4).

The UV/Vis spectra of $\mathbf{3}$ and $\mathbf{4}$ overlap exhibiting molar absorptivities of 16000 and $12000 \mathrm{M}^{-1} \mathrm{~cm}^{-1}(320 \mathrm{~nm})$, respectively, indicating that a small inner-filter effect will inhibit the rate of photocyclization. ${ }^{13}$ Regardless, we monitored the reaction as a function of residence time by UV/Vis $(0.12 \mathrm{~min}$ to $10 \mathrm{~min}$; Fig. 1). The spectra exhibit a well-defined isosbestic point indicating that the photocyclization proceeds from 3 to 4 via no observable intermediate (Fig. 1B), ${ }^{\mathbf{1 4}}$ consistent with a rate-determining photoelectrocyclization followed by rapid loss of $\mathrm{HBr}$ (Fig. 3). Crude ${ }^{1} \mathrm{H}-\mathrm{NMR}$ spectra recorded after each residence time revealed that the reaction proceeds cleanly from 3 with only a small amount of by-product formed (5). Fig. 2 features ${ }^{1} \mathrm{H}$-NMR data for a segment of the aromatic region. Product is formed even at residence times of just $0.12 \mathrm{~min}$ and the reaction is near complete in $20 \mathrm{~min}$. By-product to product
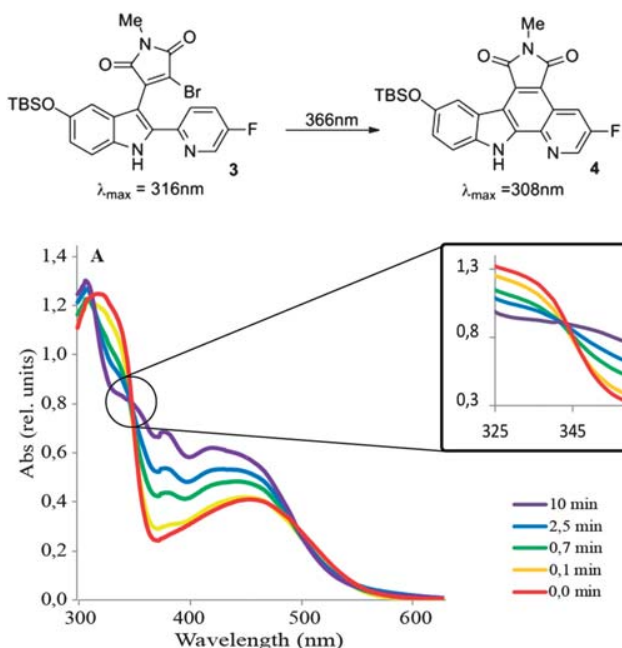

Fig. 1 Spectra information for photocyclization (A) spectra collected at various residence times $-2 \mathrm{mg}$ per each run. (B) Enlarged isosbestic point.

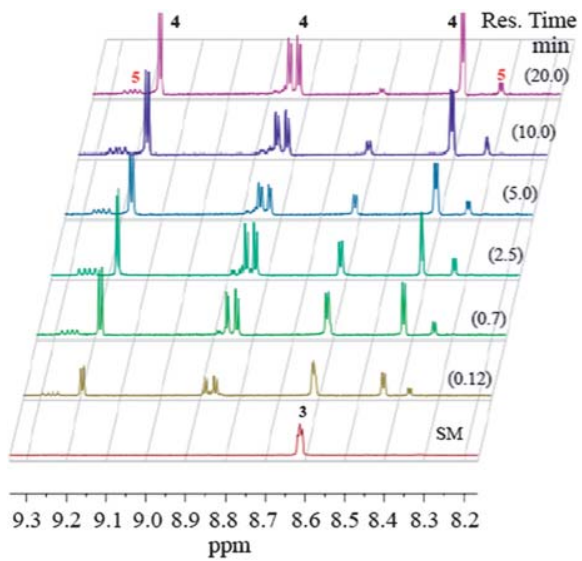

Fig. $2{ }^{1} \mathrm{H}-\mathrm{NMR}$ data collected at noted residence times for the reaction depicted in Fig. $3\left(\mathrm{DMSO}_{-} \mathrm{d}_{6}\right)$.

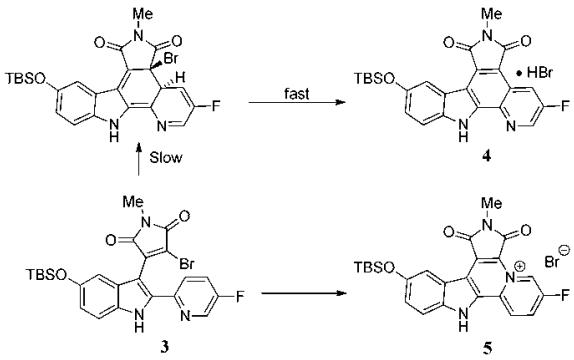

Fig. 3 Product and by-product produced by irradiation of $\mathbf{3}$
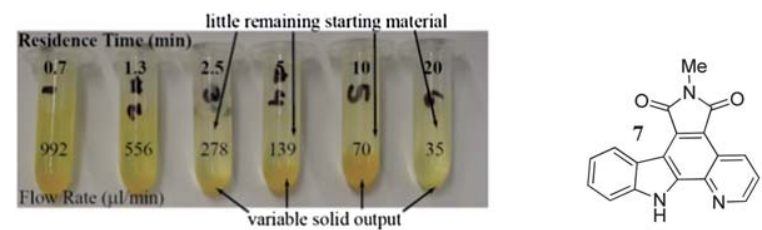

Fig. 4 Some products such as 3 precipitate, making higher flow rates necessary to remove solid from the reactor.

ratio decreases from $1: 3$ to $1: 8$ from earliest to latest residence times. NMR data for the by-product are consistent with the previously described structure 5 shown in Fig. 3.,15

The observation that 4/5 increases with time suggests that 5 forms directly from 3 with a slower rate constant compared to the formation of $\mathbf{4}$, and that 5 can revert back to $\mathbf{3}$. Both the NMR and UV/Vis data support the model that 3 proceeds directly to product via intermediates too short-lived to be observed by these techniques. In addition, these data indicate that the desired photoelectrocyclizations occur cleanly under continuous flow conditions (see Fig. 5 and text below).

The method's generality was demonstrated through the synthesis of 10 pyridocarbazoles (4 and 6-14). The substrates fit into two categories: high and low solubility in toluene. Substrates exhibiting low solubility yielded products that precipitated out of solution (Fig. 4). Fortunately, we observed no

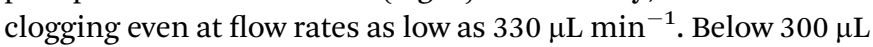
$\min ^{-1}$, we observed variable amounts of solid emerging from the reactor as well as solid left in the reactor once the experiment was concluded. The insoluble substrates typically lacked a solubilizing group such as a silyl imide or ether. Regardless,

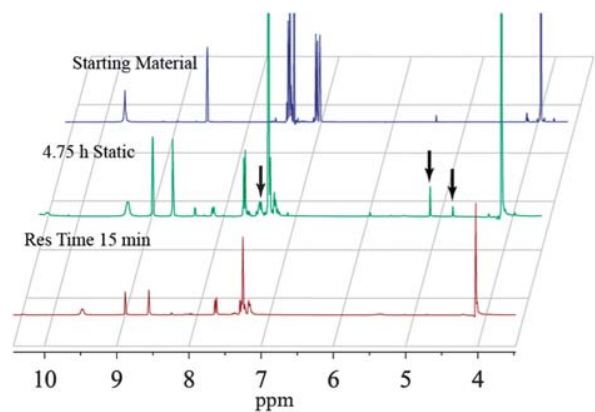

Fig. 5 Comparison of starting material and $\mathbf{1 3}$, static irradiation (4.75 h) to 15 min residence time irradiation. 
yields were good to excellent, such that some products showed no evidence of impurities by NMR (>95\% pure). ${ }^{15}$ Most reactions required only a silica plug to remove the pyridinium by-product described above.

Flow methods are more attractive than batch for preparing pyridocarbazoles because the residence time is short $(<20 \mathrm{~min})$ relative to batch $(>5 \mathrm{~h})$. Comparison of the starting material, product (13) from flow and product (13) from batch irradiation shows distinct differences (Fig. 5). For the batch reactor case, significant amounts of a by-product form (arrows) with an $R_{\mathrm{f}}$ immediately above the desired product. This emerging byproduct hampers purification.

Preparing the pyridocarbazoles rapidly enabled comparison of the photophysical properties. ${ }^{16}$ These fluorophores are interesting because they can have three orthogonal points of attachment (Fig. 6). Most exhibit a blue-green emission, but when strong $\pi$ donors are present, the emission is red-shifted to yellow/orange color (10). As representatives, we measured photophysical data for 11-14 at the same concentration (Fig. 7). This relative data indicates that 11/14 are $100 \times$ more fluorescent than 12/13 (see inset for fluorescent signal of 12/13). ${ }^{17}$ Compounds 11/14 have large Stokes shifts, $74 \mathrm{~nm} / 83 \mathrm{~nm}$, and ns decay times (both $c a$. $1.5 \mathrm{~ns}$ ), making them similar to probes such as Cy5. While we have yet to collect quantum yield data, the ease with which these chromophores can be modified combined with their promising photophysical properties indicates that pyridocarbazoles could be very attractive for bioconjugation applications. ${ }^{18}$

To demonstrate that these chromophores have potential as bioprobes, macrophage cell line RAW 264.7 was treated with compounds 7 and 8 for $20 \mathrm{~min}$ at $15 \mu \mathrm{g} \mathrm{mL}{ }^{-1}$ concentration

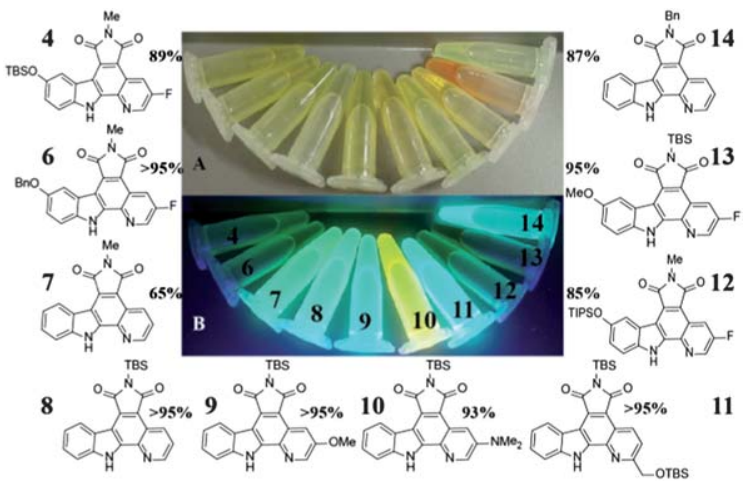

Fig. 6 Reaction scope, isolated yields and qualitative evaluation of product absorption (A) and fluorescence (B) (ex. $366 \mathrm{~nm}) .^{13}$

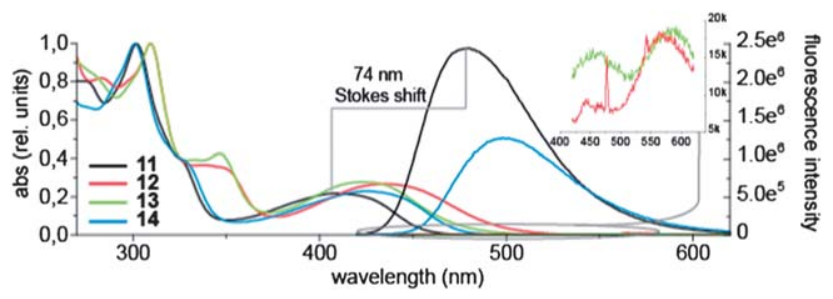

Fig. 7 Photophysical properties of 11-14 measured in $\mathrm{CHCl}_{3}(0.1 \mathrm{mM})$.

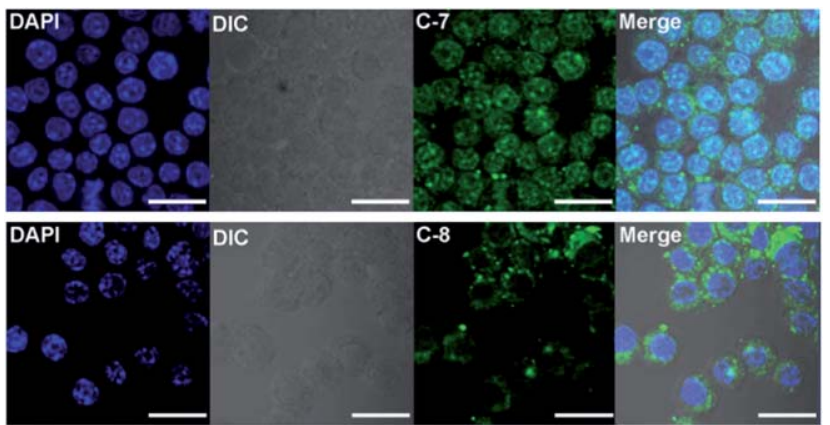

Fig. 8 LSM image of RAW (264.7) cells treated with compound 7 (top panel) and 8 (bottom panel). DAPI was used to stain the nucleus (blue). Scale bar represents $10 \mu \mathrm{m}$.

with a final DMSO content of $0.5 \%$. The treated cells were imaged using aLSM-700 confocal microscope (Carl Zeiss AG; FITC channel) to detect the localization of the compounds. As can be seen in Fig. 8, the chromophores are easily observed and appear localized within membranes. This proof of concept illustrates that these chromophores remain fluorescent under biological conditions.

We have demonstrated that a flow photoreactor is an excellent tool to produce pyridocarbazoles. The reaction occurs with no observable intermediates. Considering that $366 \mathrm{~nm}$ light is unlikely to break $\mathrm{C}-\mathrm{Br}$ bonds, we propose that this reaction proceeds via a rate-limiting $[6 \pi]$-cyclization followed by rapid extrusion of $\mathrm{HBr}$ to yield the desired products. Comparing long and short irradiation times, we have found that long irradiation results in formation of a new unwanted product that would be challenging to remove. The rapid and clean conversions are in part due to the high photoflux provided by the small dimensions of the photoreactor. These data demonstrate that the study and synthesis of compounds via photoelectrocyclizations benefit from being run in flow and that pyridocarbazoles are exciting from the standpoint of both metal coordination and photophysics. Furthermore, we have demonstrated that these compounds exhibit interesting photophysical properties including large Stokes shifts and are bright under physiological conditions. Strong $\pi$-donors such as dimethylamine result in significant red shifting of the fluorescence emission, indicating that the color of these chromophores can readily be tuned. We are now working to develop novel bioprobes based on the pyridocarbazole core.

\section{Experimental section}

The monobromides were synthesized according to published procedures. See ESI for experimental details. $\dagger$ A representative photocyclization: compound $3(33 \mathrm{mg}, 0.062 \mathrm{mmol}, 33 \mathrm{~mL}$ Toluene) was filtered through a 0.45 micro PTFA syringe filter and the solution was primed into a Vapourtec R2C+ system. The solution was pumped through a $5 \mathrm{~mL}$ photoreactor at $333 \mu \mathrm{L}$ $\min ^{-1}$ (15 min res time). The desired material was collected and concentrated to yield a dark orange solid and chromatographed over silica gel using a $3.5 \mathrm{Hex}, 1.52 \% \mathrm{Et}_{3} \mathrm{~N} /$ EtOAc solvent system $\left(R_{\mathrm{f}}-0.21\right)$. The fractions containing product were concentrated to yield $25 \mathrm{mg}$ ( $89 \%$ yield) of an orange solid. 


\section{Acknowledgements}

We thank the Max Planck Society for generous financial support. E.M. thanks the US National Institutes of Health for financial support (CA114046). M.D. thanks the Stiftung der Deutschen Wirtschaft for a stipend.

\section{Notes and references}

1 E. Meggers, Angew. Chem., Int. Ed., 2011, 50, 2442.

2 L. Feng, Y. Geisselbrecht, S. Blanck, A. Wilbuer, G. E. AtillaGokcumen, P. Filippakopoulos, K. Kräling, M. A. Celik, K. Harms, J. Maksimoska, R. Marmorstein, G. Frenking, S. Knapp, L.-O. Essen and E. Meggers, J. Am. Chem. Soc., 2011, 133, 5976; H. Bregman, D. S. Williams and E. Meggers, Synthesis, 2005, 1521; N. Pagano, J. Maksimoska, H. Bregman, D. S. Williams, R. D. Webster, F. Xue and E. Meggers, Org. Biomol. Chem., 2007, 5, 1218.

3 C. L. Davies, E. L. Dux and A.-K. Duhme-Klair, Dalton Trans., 2009, 10141; C.-M. Che and F.-M. Siu, Curr. Opin. Chem. Biol., 2010, 14, 255.

4 G. E. Atilla, D. S. Williams, H. Bregman, N. Pagano and E. Meggers, ChemBioChem, 2006, 7, 1443.

5 For examples of photoelectrocyclizations see: M. P. Cava, P. Steren and K. Wakisaka, Tetrahedron, 1973, 29, 2245; T. Bach and J. P. Hehn, Angew. Chem., Int. Ed., 2011, 50, 1000. 6 Representative photocyclizations: M. Oelgemoller, R. Frank, P. Lemmen, D. Lenoir, J. Lex and Y. Inoue, Tetrahedron, 2012, 68, 4048; L. Jierry, S. Harthong, C. Aronica, J. C. Mulatier, L. Guy and L. S. Guys, Org. Lett., 2012, 14, 288; J. Ho, T. H. Lee, C. K. Lo and C. L. Chuang, Tetrahedron Lett., 2011, 52, 7199; H. Li, K. H. He, J. Liu, B. Q. Wang, K. Q. Zhao, P. Hu and J. Z. Shi, Chem. Commun., 2012, 48, 7028; A. C. Hernandez-Perez, A. Vlassova and S. K. Collins, Org. Lett., 2012, 14, 2988.

7 F. B. Mallory and C. W. Mallory, Photocyclization of Stilbenes and Related Molecules, Org. React., 1984, 30, 1-456.

8 For general discussion of the benefits of microreactor-based chemistry see: B. P. Mason, K. E. Price, J. L. Steinbacher, A. R. Bogdan and D. T. McQuade, Chem. Rev., 2007, 107, 2300; J. P. Knowles, L. D. Elliott and K. I. Booker-Milburn, BJOC, 2012, 8, 2025-2052; N. G. Anderson, Org. Process Res. Dev., 2012, 16, 852-869; Y. Zhang, M. L. Blackman, A. B. Leduc and T. F. Jamison, Angew. Chem., Int. Ed., 2013,
52, 4251-4255; S. G. Newman and K. F. Jensen, Green Chem., 2013, 15, 1456-1472.

9 F. Lévesque and P. H. Seeberger, Angew. Chem., Int. Ed., 2012, 51, 1706; F. Bou-Hamdan and P. H. Seeberger, Chem. Sci., 2012, 3, 1612; F. Lévesque and P. H. Seeberger, Org. Lett., 2011, 13, 5008; S. R. Andrews, J. J. Becker and M. R. Gagné, Angew. Chem., Int. Ed., 2012, 51, 4140; J. W. Tucker, Y. Zhang, T. F. Jamison and C. R. J. Stephenson, Angew. Chem., Int. Ed., 2012, 51, 4144; D. C. Harrowven, M. Mohamed, T. P. Goncalves, J. R. Whitby, D. Bolien and H. F. Sneddon, Angew. Chem., Int. Ed., 2012, 51, 4405.

10 Cleavage of $\mathrm{C}-\mathrm{Br}$ bonds is thought to require wavelengths below $360 \mathrm{~nm}$. See: J. Grimshaw and A. P. de Silva, Chem. Commun., 1980, 304; S. M. Kupchan and H. C. Wormser, Tetrahedron Lett., 1965, 6, 359.

11 B. D. A. Hook, W. Dohle, P. R. Hirst, M. Pickworth, M. B. Berry and K. I. Booker-Milburn, J. Org. Chem., 2005, 70, 7558.

12 Vapourtec Ltd. http://www.vapourtec.co.uk is gratefully acknowledged for providing $\mathrm{R} 2 \mathrm{C}+$ and $\mathrm{R} 4$ flow-chemistry systems.

13 For general treatments of the inner filter effect see: D. Lavabret, G. Levy, J. P. Laplante and J. C. Micheau, J. Phys. Chem., 1988, 92, 16; B. Borderie, D. Lavabre, J. C. Micheau and J. P. Laplante, J. Phys. Chem., 1992, 96, 2953; J. R. Lakowicz, Principles of Fluorescence Spectroscopy, Springer, Singapore, 3rd edn, 2006.

14 A. E. Croce, Can. J. Chem., 2008, 86, 918.

15 All compounds matched the characterization data referenced for each compound. For those compounds lacking a citation, we provide characterization information in the ESI. $\dagger$

16 For an early reference to fluorescence of pyridocarbazoles see: M. Kulka and R. H. F. Manske, Can. J. Chem., 1952, 30, 711.

17 The origin of the quenching observed for compounds 12 and 13 is yet to be determined. Possible explanations being considered are side chains enabling non-radiative relaxation or that the fluorine present introduces low-lying $\pi \sigma^{*}$ states - see: M. Z. Zgierski, T. Fujiwara and E. C. Lim, J. Chem. Phys., 2005, 122, 144312 or that the fluorine present lowers the indole $\mathrm{N}-\mathrm{H} \quad \mathrm{p} K_{\mathrm{a}}$ facilitating photoinduced proton transfer.

18 L. I. Willems, N. Li, B. I. Florea, M. Ruben, G. A. van der Marel and H. S. Overkleeft, Angew. Chem., Int. Ed., 2012, 51, 4431. 